\title{
A STUDY OF THE POLARIZATION UPON A THIN METAL PARTITION IN A VOLTAMETER. II.
}

\author{
By John Daniel.
}

$T^{N}$ this paper two questions will be discussed : first, the passage of ions through a gold-leaf partition in a voltameter; second, the minimum current strength at which the ions are deposited visibly upon the partition for various electrolytes. This will be called the "critical current." This paper is a continuation of the work done last spring in Berlin in the quantitative measurement of the polarization upon metal partitions ranging in thickness from $0.0001 \mathrm{~mm}$. to $0.02 \mathrm{~mm}$. for various current strengths in a 30 per cent $\mathrm{H}_{2} \mathrm{SO}_{4}$ voltameter. In those experiments there was no development of gas nor polarization on a gold-leaf partition (o.ooo I $\mathrm{mm}$. thick) for the highest current used, which was four-tenths to five-tenths ampere.

The present apparatus consists essentially of a glass voltameter vessel with platinum electrodes separated by the metal partition uncler investigation, so that there is no path for the current except through this partition, an accurate instrument for measuring current, and a strong, steady battery. The voltameter consists of an outer glass jar $8 \mathrm{~cm}$. high, $8 \mathrm{~cm}$. wide, and $8 \mathrm{~cm}$. long; and an inner glass jar $8 \mathrm{~cm}$. high, $5 \mathrm{~cm}$. wide, and $5 \mathrm{~cm}$. long, placed inside the first jar. A platinum cathode, suspended by a platinum wire, is placed inside the inner jar; and a similar electrode serves as anode in the larger jar, though a copper anode was sometimes used when the electrolyte was $\mathrm{CuSO}_{4}$. A hole $2 \mathrm{~cm}$. in diameter was bored in one side of the smaller jar. Glass plates $4 \mathrm{~cm}$. wide, $6 \mathrm{~cm}$. long, and I $\mathrm{mm}$. thick were bored with a hole $1.5 \mathrm{~cm}$. in diameter. Powdered sealing-wax was placed around the edge of this hole and melted; the gold-leaf was secured to the melted 
sealing-wax. This plate was then securely sealed over the hole of the inner jar, so that there was no possible leakage. The voltameter was then carefully filled, keeping the liquid inside and outside on the same level so as not to break the gold-leaf partition, and was then ready for use.

To measure the current, a Thomson composite electric balance and a Weston double-scale ammeter were used in series with the voltameter. The two instruments were found to agree so well that the Weston ammeter was used alone for most of this work, as it was much more convenient to read.

The battery consisted of 25 accumulators of 350 ampere-hours capacity, and an electromotive force of 50 volts. The current strength was adjusted to any desired value by resistance in series, which could be varied at pleasure between zero and I2,000 ohms. For sealing-wax, pure rosin and beeswax (without coloring-matter) was used, mixed in such proportion as to give a low melting-point. The gold-leaf used was bought in Nashville, and is known to the trade as "XX." It is about $0.000 \mathrm{Imm}$. thick. Careful selection was made of such parts of the gold-leaf as were found, upon holding up to the light, to be free from small holes. It has already been observed, in Part I. of this paper, that when $\mathrm{CuSO}_{4}$ was used as the electrolyte, and the current was over 0.3 ampere, copper was deposited on the rim of the gold-leaf, which was necessarily larger than the hole in the glass plate. In this work it was found necessary to remove this gold quite close up to the edge of the hole by scraping it off, as was first tried, or by covering it carefully with sealing-wax, which was found both easier and better. This was accomplished by melting the sealing-wax over the gold with a hot brass hammer of peculiar shape made for the purpose. The wax could thus be made to flow quite close to the edge of the hole. This left only that part of the gold exposed which was immediately over the hole. To neglect this was in all cases to reduce the critical current, the deposit of the cathion appearing first on that part of the gold-leaf which was nearest the anode and farthest from the opening. 
Passage of the Ions through the Gold-leaf Partition.

To test this, a $\mathrm{I} 7$ per cent $\mathrm{CuSO}_{4}$ solution (i.e. I g. $\mathrm{CuSO}_{4}$ to 5 c.c. $\mathrm{H}_{2} \mathrm{O}$ ) was used in the outside vessel (anode side of the voltameter), and $\mathrm{H}_{2} \mathrm{SO}_{4}$ (3O per cent solution, Sp. Gr. I.23) in the inside vessel (cathode side of the voltameter). These solutions being separated by the gold-leaf partition, the appearance of the ions upon the electrodes and upon the partition, when the current was closed, was noted.

The first method of observation was to close the circuit upon the voltameter, read the current strength by the ammeter, and, at stated intervals, weigh the copper deposited on the cathode. This gave Table V., where it may be seen that the amount of copper deposited was very small at first, not more than 2 per cent or 3 per cent the first hour, but increased rapidly with the time. This did not settle the question as to whether the current caused the copper to pass through the gold-leaf partition or not.

The second method was to set up two exactly similar voltameters at the same time, close the circuit on one, leaving the other open, and, at stated intervals, to weigh the copper deposited on the cathode of the voltameter through which the current had passed, at the same time making a quantitative analysis of the solution on the cathode side of both the open and the closed voltameters. This was done by extracting ro c.c. from each with a pipette, and depositing the copper electrolytically in two similar platinum crucibles, connected in series. Equilibrium was maintained in the voltameter by adding Io c.c. of the 30 per cent $\mathrm{H}_{2} \mathrm{SO}_{4}$ solution to replace the Io c.c. thus removed. Knowing the volume of solution in each voltameter, these analyses were sufficient to determine the total amount of copper that had passed through the partition during the same interval for each voltameter. Table VI. gives the results. "Here it was observed that imperceptible differences in the specimens of gold-leaf were sufficient to cause enough difference in the diffusion to leave the question unsettled. The amount passing the partition of the open voltameter was as often greater than that of the closed voltameter as it was less. It was now evidently necessary to test one and the same gold-leaf 
partition for diffusion, with circuit open and closed successively. This leads to the third method, the results of which are shown in Table VII.

It is thought that this method is entirely free from objection or serious error; it leads to the conclusion that the current does not sensibly affect the diffusion of $\mathrm{CuSO}_{4}$ and $\mathrm{H}_{2} \mathrm{SO}_{4}$ through the gold-leaf partition. This method, in detail, was to set up two similar voltameters at the same time, leaving both open and mak-

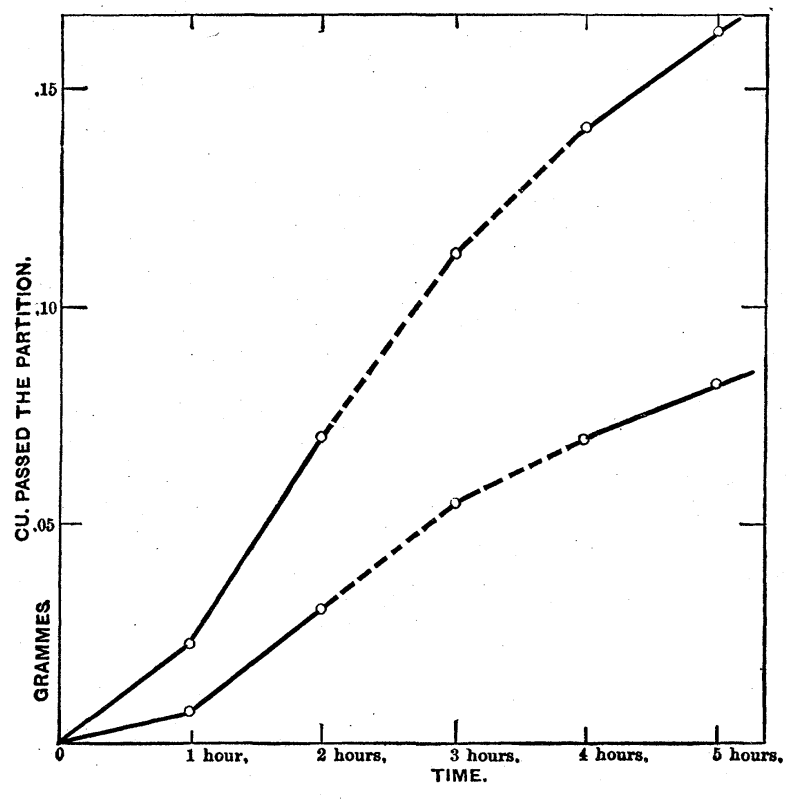

Fig. 5.

ing quantitative analyses at stated intervals; then, closing the current through both in series, to again make quantitative analyses of the solution on the cathode side, and to weigh the copper on the cathodes; finally, to break the circuit and again repeat the analyses. Curves plotted (see Fig. 5) from these results show no break nor change of slope for the intervals during which the current was passing. In the foregoing experiments there was no deposit of copper on the gold-leaf partition, provided the current was less than about 0.3 of an ampere. The time curves for the 
two specimens of gold-leaf are not identical, showing a different rate of diffusion, but are quite similar in shape. Using a copper anode, there was no visible gas on the anode, but the anode was dissolved by the current in the usual manner. Using a platinum cathode and a platinum anode, there was, of course, an escape of gas from the anode proportional to the current strength. Gas always escaped from the platinum cathode, but proportionally less as the amount of copper deposited increased. In the case where the partition was removed and the solutions thoroughly mixed, there was no gas, but the full amount of copper deposited on the cathode. Thus it seems that the passage of the current in such a voltameter is not accomplished by the passage of the copper through the gold-leaf partition. Some of the $\mathrm{CuSO}_{4}$ passes the partition by diffusion, and then does its proportional part of the conduction of the mixed solution of $\mathrm{CuSO}$ and $\mathrm{H}_{2} \mathrm{SO}_{4}$, which accounts for the increased per cent of copper deposited on the cathode, as the interval, from the time the voltameter was filled, increases.

In the time curves which may be constructed from Table VII. (see Fig. 5) it will be noticed that the amount of copper at the end of the first interval seems too small, causing a similar bend in both curves. This is doubtless due to the fact that the current was not continued long enough to deposit all the copper in the Io c.c. sample. The amount of $\mathrm{CuSO}_{4}$ present being very small, it would be deposited very slowly; and the circuit should have remained closed several hours instead of less than an hour, as was the case. A similar bend occurs in both curves, because the specimens were analyzed in series and the same defect applies to both alike. If the current was increased beyond about 0.3 ampere, with $\mathrm{CuSO}_{4}$ and $\mathrm{H}_{2} \mathrm{SO}_{4}$ as the solutions, separated by a gold-leaf partition, there was a development of gas and copper on the partition. This brings us to the second problem, the determination of the minimum current strength at which the ions are deposited visibly on the gold-leaf partition for various electrolytes. 


\section{Critical Current Density for Gold-leaf.}

This part of the investigation consists simply in closing the circuit on the voltameter with a high auxiliary resistance, slowly increasing the current by decreasing the resistance, and observing at what current strength bubbles of gas or deposit of metal begin to appear upon the partition. Table VIII. shows these values for various solutions used as electrolytes, with a gold-leaf partition. Table IX. gives the results in 30 per cent $\mathrm{H}_{2} \mathrm{SO}_{4}$ for aluminum-leaf, platinum-leaf, and gold-leaf, respectively. Table IX. shows the same for gold-leaf partition in $\mathrm{H}_{2} \mathrm{SO}_{4}$ of various concentrations from 100 per cent (?) to 0.5 per cent. Unfortunately the importance of the concentration of the solution in affecting the value of the "critical current" was not noted until after several of the solutions had been tested and thrown away without measuring their concentration or specific gravity, which therefore are not given for those cases. The specific gravity of those solutions for which it is given was.determined by a very sensitive and accurate set of hydrometers reading directly to 0.00I. Table IX. gives the results for 30 per cent $\mathrm{H}_{2} \mathrm{SO}_{4}$, with platinum partitions of various thicknesses; also of a "thick" platinum partition perforated with $\mathrm{I}, 2,3$, and 4 holes successively, each $0.5 \mathrm{~mm}$. in diameter. This is important in showing that the very small holes which may have existed in the carefully selected gold-leaves used as partitions, could not have had much, if even a sensible, influence on the value of the critical current. Table $\mathrm{X}$. shows the interesting case of a $0.02 \mathrm{~mm}$. paladium partition in 30 per cent $\mathrm{H}_{2} \mathrm{SO}_{4}$. The values given in the tables are in most cases the mean of several determinations which differed but slightly.

The importance of having the edges of the partition covered well up to the edge of the hole in the glass was emphasized in this work on account of the fact that the anode was usually placed on one side, and sometimes even at the back of the inner vessel, instead of in the front, in order not to obstruct a free inspection of the partition, and to avoid the disturbance of the gas escaping from the anode, as this was considerable with the strongest currents used; i.e. Io to 12 amperes. Thus one edge of the 
exposed partition being nearer to the anode than the opening, the deposit would always begin first on the nearest edge.

Inspection of the tables will show that in 30 per cent $\mathrm{H}_{2} \mathrm{SO}_{4}$ the gold-leaf partition will pass about ten amperes before gases are developed upon it. Platinum-leaf and aluminum-leaf showed

TABLE V.

A $17 \%$ SOLUTION OF $\mathrm{CUSO}_{4}$ WITH COPPER ANODE SEPARATED BY A GOLD-LEAF PARTITION FROM A $30 \%$ SOLUTION OF $\mathrm{H}_{2} \mathrm{SO}_{4}$ WITH PLATINUM CATHODE.

\begin{tabular}{|c|c|c|c|c|c|c|}
\hline $\begin{array}{l}\text { Time in } \\
\text { minutes. }\end{array}$ & $\begin{array}{l}\text { Current in } \\
\text { amperes. }\end{array}$ & \multicolumn{2}{|c|}{$\begin{array}{l}\text { Cu deposited on } \\
\text { cathode in grams. }\end{array}$} & \multicolumn{2}{|c|}{$\begin{array}{l}\text { Ratio of } \mathrm{Cu} \text { to } \\
\text { current. }\end{array}$} & \\
\hline 30 & 0.175 & \multicolumn{2}{|c|}{0.0030} & \multicolumn{2}{|c|}{$3 \%$} & \\
\hline $\begin{array}{l}33 \\
40 \\
40 \\
45\end{array}$ & $\begin{array}{l}0.205 \\
0.206 \\
0.127 \\
0.054\end{array}$ & \multicolumn{2}{|c|}{$\begin{array}{l}0.0765 \\
0.0920 \\
0.0700 \\
0.0380\end{array}$} & \multicolumn{2}{|c|}{$\begin{array}{l}58 \% \\
57 \% \\
70 \% \\
80 \%\end{array}$} & $\begin{array}{l}\text { After standing } \\
\text { from Saturday to } \\
\text { Monday. }\end{array}$ \\
\hline & & No. $x$. & No. 2. & No. I. & No. 2. & \\
\hline 30 & 0.132 & 0.0020 & 0.0766 & $2.6 \%$ & $99.0 \%$ & $\begin{array}{l}\text { Voltameters in } \\
\text { series. }^{1}\end{array}$ \\
\hline $\begin{array}{l}30 \\
52\end{array}$ & $\begin{array}{l}0.147 \\
0.152\end{array}$ & $\begin{array}{l}0.0270 \\
0.0453\end{array}$ & $\begin{array}{l}0.0850 \\
0.0950\end{array}$ & $\begin{array}{l}31.0 \% \\
47.6 \%\end{array}$ & $\begin{array}{r}99.0 \% \\
100.0 \%\end{array}$ & $\begin{array}{l}\text { After some } \\
\text { hours. }\end{array}$ \\
\hline 65 & 0.035 & 0.0022 & 0.0026 & $5.0 \%$ & $5.7 \%$ & $\begin{array}{c}\text { Fresh } \\
\text { solutions. }\end{array}$ \\
\hline
\end{tabular}

Remarks. - 1 The partition in No. 2 broke before the current was closed. 2 Partition of No. 1, single gold-leaf ; of No. 2, double.

sensibly the same "critical current," rather less for the aluminum, which was, however, thicker though not so free from holes.

A solution of $\mathrm{CdI}_{2}$ showed regular deposit of both cadmium and iodine upon the partition for the weakest current to 0.001 ampere. This case was peculiar in having both ions solids, and indicated as a consequence that neither would pass through the gold-leaf partition. 
Using 9 per cent $\mathrm{AgNO}_{3}$ solution, $\mathrm{Ag}_{2} \mathrm{O}_{2}$ was deposited on the anode, but this came about by a secondary action at the anode; and though we have in this case also two solids deposited on the electrodes as the result of the electrolysis, one of them is not primarily a solid, and the critical current is of the order of magni-

\section{TABLE VI.}

TO TEST DIFFUSION OF $17 \% \mathrm{CUSO}_{4}$ AND $30 \% \quad \mathrm{H}_{2} \mathrm{SO}_{4}$ WITH CURRENT PASSING IN VOLTAMETER NO. I, AND NO CURRENT PASSING IN NO. 2.

\begin{tabular}{|c|c|c|c|c|c|c|c|c|c|c|}
\hline \multirow{2}{*}{$\begin{array}{l}\text { Time in } \\
\text { minutes. }\end{array}$} & \multicolumn{2}{|c|}{$\begin{array}{l}\text { Current in } \\
\text { amperes. }\end{array}$} & \multicolumn{2}{|c|}{$\begin{array}{l}\text { Cu on } \\
\text { cathode. }\end{array}$} & \multicolumn{2}{|c|}{$\begin{array}{l}\text { Per cent of } \\
\text { Cu to current. }\end{array}$} & \multicolumn{2}{|c|}{$\begin{array}{l}\text { Cu in ro c.c. } \\
\text { solution. }\end{array}$} & \multicolumn{2}{|c|}{$\begin{array}{c}\text { Total Cu } \\
\text { passed the gold. }\end{array}$} \\
\hline & No. $\mathrm{r}$. & No. 2. & No. 1. & No. 2. & No. I. & No. 2. & No. I. & No. 2. & No. $x$. & No. 2. \\
\hline 92 & 0.0505 & 0.0 & 0.0058 & 0.0 & 6.4 & 0.0 & 0.0020 & 0.0023 & 0.0308 & 0.0300 \\
\hline 87 & 0.0530 & 0.0 & 0.0143 & 0.0 & 15.8 & 0.0 & 0.0040 & 0.0050 & 0.0643 & 0.0650 \\
\hline
\end{tabular}

Fresh solutions and single gold-leaf partitions.

\begin{tabular}{r|c|c|c|c|c|c|c|c|c|c}
\hline 45 & 0.1500 & 0.0 & 0.0022 & 0.0 & 1.7 & 0.0 & 0.0043 & 0.0040 & 0.0550 & 0.0480 \\
65 & Broke. & 0.0 & - & 0.0 & - & 0.0 & - & 0.0060 & - & 0.0760 \\
$18 \mathrm{hr}$. & - & 0.0 & - & 0.0 & - & 0.0 & - & 0.0256 & - & 0.3172 \\
\hline
\end{tabular}

Fresh solutions and gold-leaf partitions.

\begin{tabular}{l|l|l|l|l|r|r|r|r|r|r}
\hline 55 & 0.0770 & 0.0 & 0.0022 & 0.0 & 5.3 & 0.0 & 0.0014 & 0.0033 & 0.0190 & 0.0410 \\
60 & 0.0770 & 0.0 & 0.0090 & 0.0 & 20.0 & 0.0 & 0.0035 & 0.0065 & 0.0540 & 0.0850 \\
60 & 0.0790 & 0.0 & 0.0142 & 0.0 & 30.8 & 0.0 & 0.0038 & 0.0084 & 0.0797 & 0.1148 \\
\hline
\end{tabular}

Began the above at $12 \mathrm{hr} .55 \mathrm{~min} .30 \mathrm{sec}$; closed at $3 \mathrm{hr} .30 \mathrm{~min} .30 \mathrm{sec}$.

tude of that for other metallic salts. A similar case was found in that of $\mathrm{MnSO}_{4}$ solution, where $\mathrm{MnO}_{2}$ was deposited on the anode. A solution of lead acetate gave $\mathrm{PbO}_{2}$ on the anode, but showed a very low " critical current."

An interesting fact is the dependence of the "critical current" upon the concentration of the electrolyte, as shown in Table IX., indicating that the "critical current" is proportional to the conductivity of the electrolyte. I have made some experiments to 
determine whether variation of the temperature has the same effect upon the "critical current" as upon the conductivity, although the results are as yet hardly sufficient to justify a conclusion. I have been entirely unable anywhere to get a series of platinum partitions of thicknesses suitable to repeat the quantitative measurement of polarization which were made in Berlin for the gold plates. Table X. for $0.02 \mathrm{~mm}$. palladium is interesting.

TABLE VII.

THIRD AND BEST METHOD.

\begin{tabular}{|c|c|c|c|c|c|c|c|c|c|c|}
\hline \multicolumn{11}{|c|}{ Fresh solutions and gold-leaf partitions. } \\
\hline \multirow{2}{*}{$\begin{array}{l}\text { Time in } \\
\text { minutes. }\end{array}$} & \multicolumn{2}{|c|}{$\begin{array}{l}\text { Current in } \\
\text { amperes. }\end{array}$} & \multicolumn{2}{|c|}{$\begin{array}{c}\text { Cu on } \\
\text { cathode. }\end{array}$} & \multicolumn{2}{|c|}{$\begin{array}{l}\text { Per cent of } \\
\text { Cu to current. }\end{array}$} & \multicolumn{2}{|c|}{$\begin{array}{l}\text { Cu in ro c.c. } \\
\text { solution. }\end{array}$} & \multicolumn{2}{|c|}{$\begin{array}{c}\text { Total Cu } \\
\text { passed the gold }\end{array}$} \\
\hline & No. $x$. & No. 2. & No. $x$. & No. 2. & No. r. & No. 2. & No. 1 . & No. 2. & No. $x$. & No. 2. \\
\hline 60 & 0.0 & 0.0 & 0.0 & 0.0 & 0.0 & 0.0 & 0.0019 & 0.0006 & 0.0228 & 0.0075 \\
\hline 60 & 0.0 & 0.0 & 0.0 & 0.0 & 0.0 & 0.0 & 0.0055 & 0.0024 & 0.0679 & 0.0306 \\
\hline \multicolumn{11}{|c|}{ Then the circuit was closed. } \\
\hline 45 & 0.10 & 0.10 & 0.0154 & 0.0060 & 35.0 & 13.7 & 0.0074 & 0.0036 & 0.1116 & 0.0540 \\
\hline 45 & 0.10 & 0.10 & 0.0205 & 0.0100 & 47.0 & 22.8 & 0.0080 & 0.0038 & 0.1467 & 0.0701 \\
\hline \multicolumn{11}{|c|}{ Again, leaving the circuit open, the following was obtained:- } \\
\hline 60 & 0.0 & 0.0 & 0.0 & 0.0 & 0.0 & 0.0 & 0.0090 & 0.0048 & 0.1667 & 0.0864 \\
\hline \multicolumn{11}{|c|}{ Filled the voltameters at $\mathrm{I2} \mathrm{hr}$.; last test for $\mathrm{Cu}$ at $5 \mathrm{hr}$. } \\
\hline $16 \mathrm{hr}$. & 0.0 & 0.0 & 0.0 & 0.0 & 0.0 & 0.0 & 0.0310 & 0.0187 & 0.5387 & 0.3200 \\
\hline
\end{tabular}

Either gold, platinum, or aluminum as thick as this behaves like a very thick plate, i.e. shows gas at once in amount corresponding to the current strength. When first set up, the $0.02 \mathrm{~mm}$. palladium partition showed a "critical current" of 0.08 ampere. After considerable use, the "critical current" has gradually, though not slowly, increased to 0.3 in 30 per cent $\mathrm{H}_{2} \mathrm{SO}_{4}$. This seems to be quite distinct from the well-known property of 
palladium of occluding gases, especially hydrogen, for this plate will pass 0.2 amperes or more for hours without showing gas, and develops gas at once for a little stronger current. The gas on the partition of palladium will cease to escape if the current be again reduced below the "critical" value. Currents of several amperes have several times been passed through this partition, developing profuse gas, and it was thought probable that the palladium was

TABLE VIII.

SHOWING MEAN MINIMUM CURRENT AT WHICH GASES DEVELOPED VISIBLY ON A GOLD-LEAF PARTITION, WITH PLATINUM ELECTRODES.

\begin{tabular}{|c|c|c|c|c|c|c|c|}
\hline \multicolumn{2}{|c|}{ Electrolyte. } & $\mathrm{CuSO}_{4} \cdot$ & $\mathrm{AgNO}_{3}{ }^{1}$ & $\mathrm{CdI}_{2}$ & $\mathrm{ZnSO}_{4}$ & $\mathrm{MnSO}_{4} \cdot{ }^{2}$ & $\mathrm{FeSO}_{4}$ \\
\hline \multirow{3}{*}{\multicolumn{2}{|c|}{ 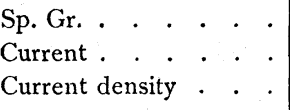 }} & $17 \%$ & $9 \%$ & & saturated & & 1.10 \\
\hline & & 0.17 & 0.40 & $0.0001-$ & 0.19 & 0.15 & 0.32 \\
\hline & & 0.10 & 0.23 & & 0.11 & 0.08 & 0.18 \\
\hline \multicolumn{2}{|c|}{ Electrolyte. } & $\mathrm{SnSO}_{4}$. & $\mathrm{NiSO}_{4}$ & $\mathrm{HgSO}_{4}$. & \multicolumn{3}{|c|}{$\mathbf{N H}_{\mathbf{4}} \mathbf{N O}_{3}$} \\
\hline \multirow{3}{*}{\multicolumn{2}{|c|}{$\begin{array}{l}\text { Sp. Gr. . } \cdot \cdot \cdot \\
\text { Current . } \cdot \cdot \\
\text { Current density }\end{array}$}} & & & & 1.05 & 1.10 & 1.135 \\
\hline & & 0.30 & 0.13 & 0.17 & 0.65 & 2.80 & 3.00 \\
\hline & & 0.17 & 0.07 & 0.10 & 0.37 & 1.60 & 1.75 \\
\hline \multirow{2}{*}{ Elec. } & \multirow{2}{*}{$\begin{array}{c}\text { Benzoate } \\
\text { of } \mathrm{Na} \text {. }\end{array}$} & \multicolumn{2}{|c|}{ Sulphate of } & \multicolumn{4}{|c|}{ Acetate of } \\
\hline & & Am. \& Fe. & Am. \& Ni. & $\mathrm{Pb}^{3}$ & Am. & Am. & $\mathrm{Na}$ \\
\hline Sp. Gr. & & & & 1.10 & 1.06 & 1.09 & sat'd \\
\hline Current . . & 0.75 & 0.18 & 0.31 & 0.018 & 1.10 & 0.70 & 0.75 \\
\hline Cur. density. & 0.43 & 0.10 & 0.18 & 0.01 & 0.63 & 0.40 & 0.43 \\
\hline
\end{tabular}

REMARKs. - ${ }^{1} \mathrm{AgO}_{2}$ formed on anode. ${ }^{2} \mathrm{MnO}_{2}$ formed. ${ }^{3} \mathrm{PbO}_{2}$ formed.

A $96 \%$ solution of acetic acid was found to have too high a resistance to give a sensible current with 50 volts, electromotive force. Benzoic acid dissolved in the same was also an insulator.

being dissolved by the 30 per cent $\mathrm{H}_{2} \mathrm{SO}_{4}$ under the action of the current. Accordingly a test of the solution was made for palladium by adding ammonia until alkaline, and then adding ammonium sulphide, which gave no indication of the presence of palladium. 
It has been observed that platinum is perfectly constant, showing the same "critical current" as often as tested. Gold is oxidized the first time the "critical current" is attained, and its value decreases on repeating the test (with the same specimen).

Efforts were made to test the critical currents for four thicknesses of gold from $0.0004 \mathrm{~mm}$. to $0.0018 \mathrm{~mm}$., in ammonium nitrate, hoping that this would not oxidize the gold; but the partitions were oxidized by currents strong enough to develop gas.

TABLE IX.

THE CRITICAL CURRENT AS AFFECTED BY STRENGTH \% OF $\mathrm{H}_{2} \mathrm{SO}_{4}$, AND NATURE OF PARTITION.

\begin{tabular}{l|c|c|c|c|c|c|c|c|c|c}
\hline Strength. & $100(?)$ & 55 & 43 & \multicolumn{3}{|c|}{30} & 22 & 15 & 4 & 0.5 \\
\hline Partition . & $\mathrm{Au}$ & $\mathrm{Au}$ & $\mathrm{Au}$ & $\mathrm{Al}$ & $\mathrm{Au}$ & $\mathrm{Pt}$ & $\mathrm{Au}$ & $\mathrm{Au}$ & $\mathrm{Au}$ & $\mathrm{Au}$ \\
Current & 0.55 & 4.5 & 8.0 & 8.0 & 10.0 & 10.0 & 8.0 & 6.0 & 1.8 & 0.23 \\
Cur. dens. & 0.31 & 2.57 & 4.57 & 4.57 & 5.71 & 5.71 & 4.57 & 3.43 & 1.03 & 0.13 \\
\hline
\end{tabular}

$30 \% \mathrm{H}_{2} \mathrm{SO}_{4}$. CRITICAI CURRENT AFFECTED BY THICKNESS OF PLATINUM PARTITION IN MILLIMETERS AND BY PUNCTURES $0.5 \mathrm{~mm}$. IN DIAMETER.

\begin{tabular}{l|c|c|c|c|c|c|c|c}
\hline \hline Thickness. & 0.00333 & 0.0050 & \multicolumn{5}{|c}{0.02} \\
\hline Holes . . . . & - & - & 0 & 1 & 2 & 3 & 4 \\
Current . . . &. & 0.090 & 0.002 & weakest & 0.07 & 0.13 & 0.20 & 0.27 \\
Current density & - & - & - & 0.04 & 0.07 & 0.115 & 0.154 \\
\hline
\end{tabular}

TABLE $X$.

INCREASING CRITICAL CURRENT OF $0.02 \mathrm{~mm}$. PALLADIUM IN $30 \%$ $\mathrm{H}_{2} \mathrm{SO}_{4}$.

\begin{tabular}{|c|c|c|c|c|c|c|c|c|c|c|}
\hline \multirow{2}{*}{\multicolumn{3}{|c|}{ Date. }} & \multicolumn{2}{|c|}{ January } & \multicolumn{6}{|c|}{ February } \\
\hline & & & $3 \mathbf{I}$ & $\overrightarrow{3^{x}}$ & 4 & 8 & 17 & 17 & 18 & 18 \\
\hline Current & . & & 0.08 & 0.10 & 0.15 & 0.17 & 0.25 & 0.26 & 0.27 & 0.27 \\
\hline Current & density. & . & 0.045 & 0.057 & 0.086 & 0.10 & 0.143 & 0.148 & 0.154 & 0.154 \\
\hline
\end{tabular}


A new specimen of the same palladium is being tested, and is showing the same phenomenon of increase of the critical current. This last specimen was carefully selected, and has no holes. Its critical current at first was 0.016 ; after. some use, it was 0.043 ampere.

I have begun to use a solution of sodium acetate, with the hope that it will not oxidize the gold. I can already say that it is at least very much less active than sulphuric acid. It also shows a

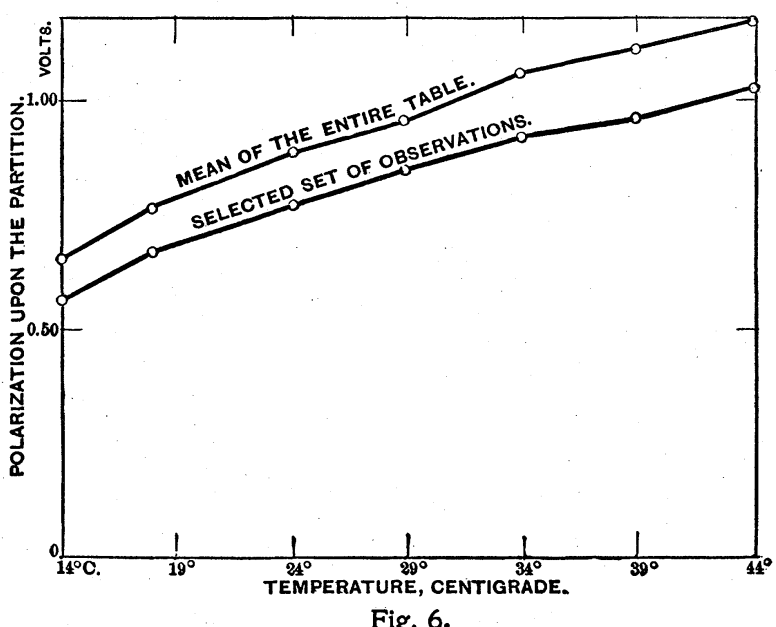

decided temperature coefficient (see Fig. 6) for the critical current. This part of the investigation will be resumed when opportunity offers.

VANDERbilt University, Nashville, Tennessee, February 22, 1893.

NoTE. - More satisfactory specimens of palladium have not yet been obtained, so the matter is left for the present with the seemingly anomalous results, recorded above, as I find them in my note-book. As regards the temperature coefficient of the "critical current density," I have had Mr. R. W. Clawson, a student in the Laboratory, make some measurements, which are tabulated below. It may be well to state that the method of observation, that of 
observing the first appearance of visible gas, is not very sensitive, because this development of gas on thin partitions is not quite sudden and sharply defined, but begins gradually, especially with very thin partitions. The probable error of a reading is, however, I think, not more than 5 per cent. Only "XX" gold-leaf has

TABLE XI.

(Double lines indicate a new partition.)

\begin{tabular}{|c|c|c|c|c|c|c|c|c|c|c|c|}
\hline \multicolumn{12}{|c|}{ Sodium acetate; Sp. Gr. = 1.06. Gold-leaf partition. } \\
\hline Temperature & • & & 22 & 24 & 26 & 29 & 30 & 33 & 35 & 24 & 27 \\
\hline Current . . & . & - & .65 & .70 & .76 & .80 & .85 & .92 & .96 & .53 & .64 \\
\hline Temperature & . & & 24 & 26 & 22 & 23 & 24 & 24 & 33 & 41 & 45 \\
\hline Current . . & . & & .54 & .60 & .53 & .57 & .59 & .77 & 1.18 & 1.33 & 1.48 \\
\hline Temperature & & & 15 & 17 & 19 & 20 & 23 & 26 & 30 & 33 & 37 \\
\hline Current . . & & & .30 & .37 & .45 & .50 & .65 & .74 & .83 & .96 & 1.02 \\
\hline \multicolumn{12}{|c|}{ New solution sodium acetate; $\mathrm{Sp} . \mathrm{Gr} .=\mathbf{x} .13$} \\
\hline Temperature & & & 23 & 27 & 23 & 28 & 24 & 30 & 35 & 38 & - \\
\hline Current. . & & - & .70 & .80 & .80 & 1.0 & .95 & 1.05 & 1.20 & 1.29 & - \\
\hline Temperature & & • & 14 & 19 & 24 & 29 & 34 & 39 & 44 & - & - \\
\hline Current . . & & • & .57 & .67 & .78 & .85 & .93 & .98 & 1.05 & - & - \\
\hline Temperature & & & 30 & 36 & 41 & 46 & 25 & 30 & 35 & 40 & 25 \\
\hline Current . . & & . & .87 & .91 & .99 & 1.1 & .71 & .76 & .86 & .94 & .60 \\
\hline Temperature & & ${ }^{\circ}$ & 30 & 35 & 40 & 45 & 25 . & 30 & 35 & 40 & 45 \\
\hline Current . . & & . & .65 & .69 & .74 & .82 & .72 & .85 & .92 & .98 & 1.05 \\
\hline Temperature & & $\cdot$ & 25 & 30 & 35 & 40 & 45 & - & - & - & - \\
\hline Current . . & & . & .72 & .85 & .92 & .98 & 1.05 & - & - & - & - \\
\hline
\end{tabular}

been used in a solution of sodium acetate. The method was to set up the voltameter with gold-leaf partition, close the circuit, and run the current up until the "critical current density" was reached. Current and temperature were recorded, the current slightly reduced and allowed to pass till the temperature had 
risen, say 5 degrees, when the current was again increased to the "critical" value for this new temperature. The limit was reached at about $45^{\circ} \mathrm{C}$., when the sealing-wax softened. Since both "critical current density" and conductivity of the electrolyte increase with temperature, effort was made to learn whether both these quantities have the same temperature coefficient, by raising the current just to the "critical" value, and, without altering the outside resistance, to observe if the increasing current, due to increasing conductivity of the electrolyte, just sufficed to maintain an incipient escape of gas at the partition. In every case the gas soon ceased to escape on being left alone, after adjusting the current to a given temperature, requiring always some reduction of the outside resistance to regain the critical current for the higher temperature. A quantitative correction for the temperature coefcient of the outside metallic resistance in the circuit would probably account for the discrepancy.

The curve plotted from the mean of all the above results gives almost a straight line.

APRIL 15, 1893. 